\title{
Correction to: Genetic homogeneity assessment of in vitro-regenerated plantlets of Nyctanthes arbor-tristis L. and comparative evaluation of bioactive metabolites and antioxidant activity
}

Sobha Chandra Rath ${ }^{1} \cdot$ Sen Seth ${ }^{1} \cdot$ Sujit K. Mishra ${ }^{1} \cdot$ Pawan K. Yadav ${ }^{2} \cdot$ Aditya K. Gupta $^{2} \cdot$ Jogeswar Panigrahi $^{1,2,3}$

Published online: 13 November 2019

(C) The Society for In Vitro Biology 2019

Correction to: In Vitro Cellular \& Developmental Biology - Plant

https://doi.org/10.1007/s11627-019-10004-8

There was an error in this article as originally published.
The surname of coauthor Sobha Chandra Rath was misspelled as "Ratha".

The original article has been corrected.

The online version of the original article can be found at https://doi.org/ $10.1007 /$ s11627-019-10004-8

\footnotetext{
Jogeswar Panigrahi

drjpanigrahi@gmail.com

1 Plant Biotechnology Laboratory, School of Life Sciences, Sambalpur University, Sambalpur, India

2 Department of Biotechnology, School of Life Sciences, Central University of Rajasthan, Kishangarh, India

3 Department of Bioscience and Bioinformatics, Khallikote University, Berhampur, India
} 